\title{
Role of diagnostic hysteroscopy in evaluating patients with abnormal uterine bleeding in a tertiary care centre
}

\author{
Apeksha M. Mohite*, Deepali S. Kapote, Michelle Fonseca
}

Department of Obstetrics and Gynaecology, LTMMC and LTMGH, Mumbai, Maharashtra, India

Received: 20 October 2021

Revised: 16 November 2021

Accepted: 17 November 2021

\section{*Correspondence:}

Dr. Apeksha M. Mohite,

E-mail: apekshamohite11@gmail.com

Copyright: () the author(s), publisher and licensee Medip Academy. This is an open-access article distributed under the terms of the Creative Commons Attribution Non-Commercial License, which permits unrestricted non-commercial use, distribution, and reproduction in any medium, provided the original work is properly cited.

\begin{abstract}
Background: Abnormal uterine bleeding is one of the commonest conditions amongst patients attending gynaecology OPD which also leads to significant disruption in a normal lifestyle. The causes of abnormal uterine bleeding are heterogeneous and complex. A systematic evaluation with detailed history and physical examination is foremost important in reaching diagnosis. Hysteroscopy is not only safe, quick and observes entire uterine cavity but also helps in precision in sampling and increases accuracy of diagnosis. It is also curative in conditions such as polyps, fibroids, uterine synechiae, menorrhagia and lost intrauterine contraceptive device. The aim of the study is to evaluate the role of hysteroscopy as a screening method in patients with AUB \& compare to their USG findings and to the histopathological reports of the endometrial biopsy.

Methods: This is a prospective observational study conducted at a tertiary healthcare centre over a period of 18 months, in 50 females belonging to pre, peri and post-menopausal age group. Sampling was done based on selection criteria after obtaining valid consent from the study group.

Results: Hysteroscopy has a definitive role in evaluation of patients presenting with abnormal uterine bleeding with high sensitivity, specificity, PPV and NPV with immediate results.

Conclusions: The above study concludes that the accuracy of diagnosing the cause of abnormal uterine bleeding is more with hysteroscopy followed by D and C then USG combined with D and C.
\end{abstract}

Keywords: Abnormal uterine bleeding, Diagnostic hysteroscopy, Dilation and curettage, Ultrasonography, Histopathological examination

\section{INTRODUCTION}

Abnormal uterine bleeding (AUB) can be defined as changes in frequency of menstruation, duration of flow or amount of blood loss. ${ }^{1,2}$ AUB is one of the most common conditions for which patients seek gynaecological consultation. As quoted by prentice A 'the most frequently encountered conditions in gynecology is abnormal uterine bleeding'. The International federation of gynaecology and Obstetrics working group on menstrual disorders has developed a classification system (PALM-COEIN) for causes of AUB in non-gravid women. There are nine main categories, which are arranged according to the acronym PALM-COEIN: polyp; adenomyosis; leiomyoma; malignancy and hyperplasia; coagulopathy; ovulatory dysfunction; endometrial; iatrogenic; and not yet classified. ${ }^{3}$ The common causes of AUB depends on the age of the patient and the likelihood of serious endometrial pathology increases with age. Also, the line of management changes as per the cause of AUB.

It is important to establish the correct diagnosis as it will help to give appropriate treatment. To diagnose the structural causes of AUB various methods used include ultrasonography, sonosalpingography, hysteroscopy and 
D and C. Primary aim is to diagnose in the most efficient and least invasive manner. ${ }^{1,4}$ For many years, diagnostic $\mathrm{D}$ and $\mathrm{C}$ was considered as an important diagnostic procedure for the diagnosis of AUB but being a blind procedure there is a likely chance to miss many diagnoses. To obtain an adequate sample of the endometrial tissue it requires skill, moreover complications like perforations, cervical tears and injuries, scar tissue formation and intrauterine adhesions are common. With the advent of hysteroscopy there is a new era for the diagnosis of AUB and it has therefore become the prime investigation of choice for the evaluation of AUB. It basically involves direct visualization of the uterine cavity so that biopsy can be taken under direct visualization. "A vigilant eye in the uterine cavity is better than numerous blind curettages" Lindmann. It is therefore considered as gold standard for diagnosis of AUB. ${ }^{5}$ AUB which is primarily associated with ovarian dysfunction and anovulation should be evaluated as follows: by doing HPE of endometrium, by using the endometrial thickness using transvaginal probe and direct visualisation of the endometrial cavity using hysteroscopy

\section{Hysteroscopy}

Hysteroscopy was first described by Panteleoni in $1869 .^{6}$ Hysteroscopy allows accurate localization of pathology under direct visualization. Thus, providing accuracy in obtaining sample which would yield positive results. Hysteroscopy is a minimally invasive intervention that can be used to diagnose and treat many intrauterine and endocervical problems. Hysteroscopic polypectomy, myomectomy, and endometrial ablation are just a few of the commonly performed procedures. It is the process of viewing and operating in the endometrial cavity through transcervical approach. The basic instrumentation in a hysteroscope is a long, narrow telescope connected to a light source (three most commonly used are tungsten, metal halide, xenon) to illuminate the area which is to be visualized. The cervix is visualized with a patient in the lithotomy position after placing a speculum in the vagina. The distal end of the telescope is then passed into a dilated cervical canal and advanced into the uterine cavity under visual guidance. The image obtained through the camera (attached to the proximal end) is then broadcast onto a large video screen. Other modifications are inflow and outflow tracts inclusion in the shaft of the telescope for fluids. Various distending medias such as carbon dioxide $\left(\mathrm{CO}_{2}\right)$, hyskon (32\% dextran 70 in dextrose), normal (physiologic) saline $(0.9 \%$ sodium chloride), glycine and sorbitol can be used to attain the desired degree of distention of the endometrial cavity, enabling visualization and operation in an enlarged area.

\section{Histopathology of endometrium in $A U B$}

The primary role of endometrial sampling in patients with AUB is to determine whether carcinomatous or premalignant lesions are present by evaluating histological samples.

\section{Role of ultrasonography in $A U B$}

Ultrasonography is a convenient, inexpensive, and noninvasive way to indirectly visualize the endometrial cavity. It is a painless, safe and convenient way to visualize the pathologies of endometrial cavity indirectly. The parameters that can be assessed on USG includes uterine size, endometrial thickness, endometrial and myometrial consistency and morphological abnormalities such as submucosal fibroids, polyp, congenital uterine anomalies, PCOS, endometrial carcinoma. Thus, USG has an important role in diagnosing certain disorder of the endometrium.

\section{Aim and objectives}

Aim of current study was to evaluate the role of hysteroscopy as a screening method in patients with AUB as compared to their USG findings and to the histopathological reports of the endometrial biopsy. Objectives of current study were to evaluate the usefulness of hysteroscopy in AUB and to determine the pattern of hysteroscopic abnormalities in abnormal uterine bleeding and to determine the histopathological features of AUB and correlate hysteroscopic findings with ultrasonographic and histopathological findings.

\section{METHODS}

This is an observational study conducted at Lokmanya Tilak Municipal Medical College and General Hospital, Mumbai, a tertiary healthcare centre over a period of 18 months from January 2018 to June 2019 in 50 females in pre, peri and post-menopausal age group.

\section{Inclusion criteria}

Patients who had Abnormal Uterine Bleeding in the Age Group of 20-60 years, both nulliparous and parous women were included in the study.

\section{Exclusion criteria}

Patients with pregnancy/abortion/ectopic pregnancy, intrauterine infections/PID/STDs, lower genital tract malignancies, pelvic deformities and medical contraindications for medical procedures were excluded from the study.

\section{Statistical methods}

Step 1: all responses were tabulated using Microsoft Excel 2016 Software. Graphical representations were made wherever necessary. Step 2: the data obtained was analysed by using SSPS Software version 22.0 Statistical tools used were; mean, standard deviation, range, proportions and percentage, Chi square test, sensitivity 
and specificity and positive predictive and negative predictive value.

\section{Procedure}

Our study includes 50 women, ages varying between 20 to 60 years with abnormal uterine bleeding who were admitted. These 50 patients were subjected to a detailed history taking which includes age, parity, date of last menstrual cycle was taken. A detailed history for ruling out any major medical or surgical illness was asked for. History to rule out bleeding disorders including history of any drug intake was taken. Patients were also asked if they had any history of intrauterine device insertion or usage of oral contraceptive pills, regular drug or hormonal preparation usage. Former gynaecological procedures and operations were recorded. A detailed menstrual history was taken and UPT was done to rule out pregnancy. Obstetric history was noted. This was followed by detailed general examination and systemic examination. A PAP smear was obtained and pelvic examination i.e., per speculum and per vaginal examination was done. Routine investigations were then conducted which included a complete hemogram, liver function and renal function test and urine routine was done. Coagulation disorders were ruled out using BT/CT, PT INR. Thyroid function test was also done to rule out endocrinological causes of abnormal uterine bleeding. All 50 patients with complaint of abnormal uterine bleeding were first evaluated with sonography followed by hysteroscopy and dilatation and curettage. The pathological findings were then correlated with ultrasound finding and diagnosis by hysteroscopy.

\section{RESULTS}

The most common presenting complaint according to this study was menorrhagia which contributed to $42 \%$, this was followed by polymenorrhagia (18\%) and dysmenorrhea (12\%) (Figure 2). Majority of these patients with abnormal uterine bleeding presented to the OPD within 1 year of onset of symptoms. The most common duration of symptoms as per our study was 6-12 months with a mean of 8.07 months and SD of 4.32 . $18 \%$ of these patients presented within 3-6 months of onset of the symptoms. Only $4 \%$ of these patients presented after one year of onset of symptoms rest presented within 3 months of suffering.

Chi square test was applied and considering $10 \mathrm{gm} \%$ as cut off value for anaemia it was observed that patients with symptoms of menorrhagia and polymenorrhea had significant blood loss so as to present with anaemia due to blood loss (Table 1). On Ultrasonographic findings the most common findings were polyp in 9 patients $(18 \%)$, this was followed by fibroid in 4 patients (8\%). $66 \%$ Of these patients showed normal findings. Rest showed adenomyosis (4\%), IUCD (2\%) and atrophy (2\%). (Figure 3).

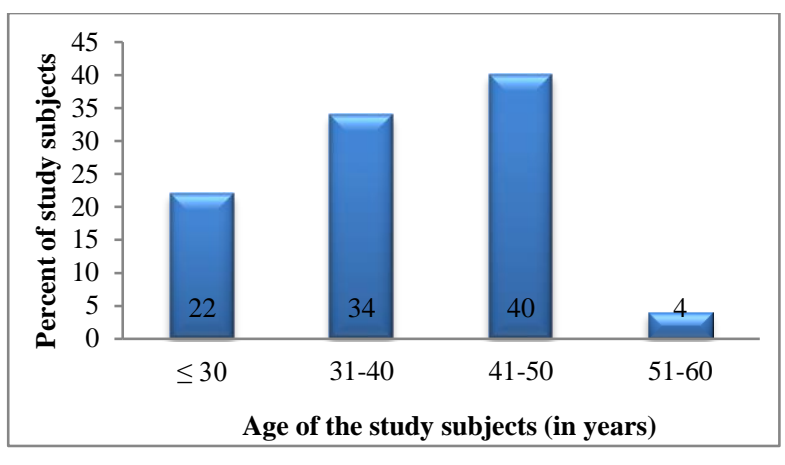

Figure 1: Distribution of age group.

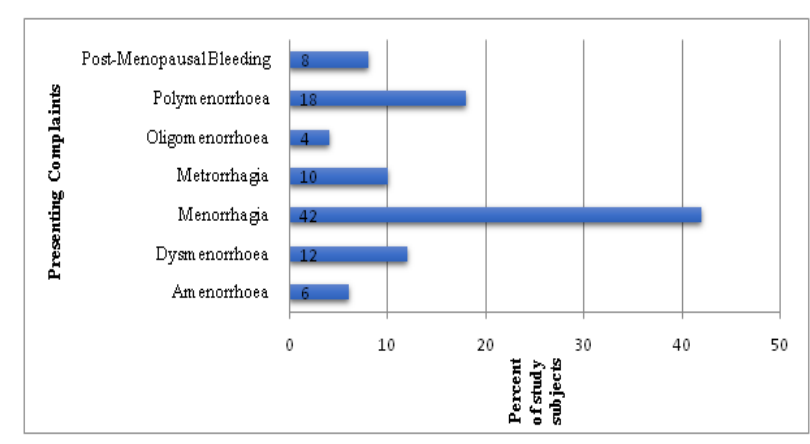

Figure 2: Distribution of study subjects according to the presenting complaints $(\mathrm{N}=50)$.

Table 1: Association between presenting complaints and anaemia $(\mathrm{N}=50)$.

\begin{tabular}{|llll|}
\hline $\begin{array}{l}\text { Presenting } \\
\text { Complaints }\end{array}$ & Anaemia & P value \\
\hline Menorrhagia & $16(76.2)$ & $5(23.8)$ & $<0.001^{*}$ \\
\hline Polymenorrhoea & $9(100.0)$ & 0 & $<0.001^{*}$ \\
\hline
\end{tabular}

Chi-Square Test, $\mathrm{P}$ Value * Significant

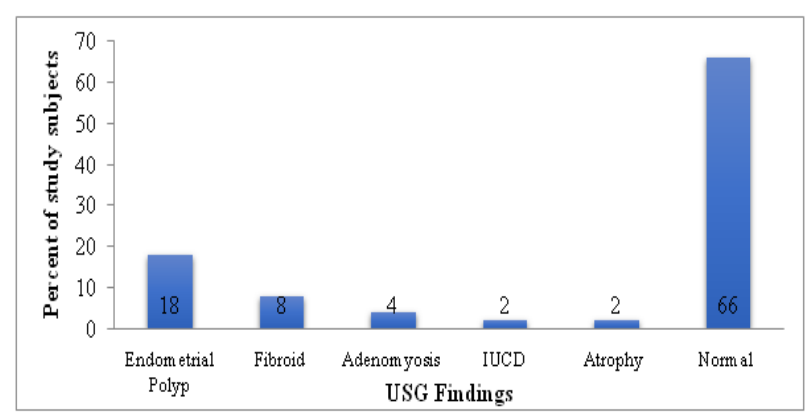

Figure 3: Distribution of study subjects according to USG findings $(\mathbf{N}=\mathbf{5 0})$.

According to as the present study, endometrial hyperplasia was encountered to $32 \%$ of patients (Figure 4). Thus, endometrial hyperplasia was found to be the most common cause of AUB which was followed by endometrial polyp. On histopathological examination, there were $22(44 \%)$ patients with normal histopathological findings, $5(10 \%)$ patients showed 
polyp, 17 (34\%) showed hyperplastic changes while 3 $(6 \%)$ had features suggestive of fibroids (Figure 5).

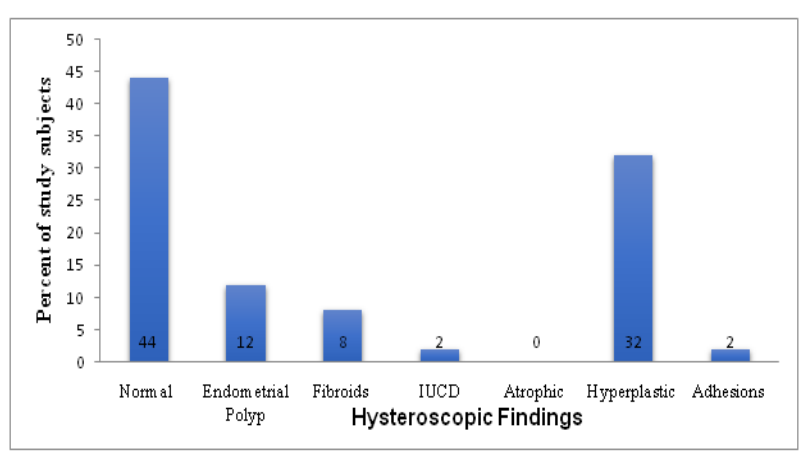

Figure 4: Distribution of study subjects according to hysteroscopic findings $(\mathbf{N}=\mathbf{5 0})$.

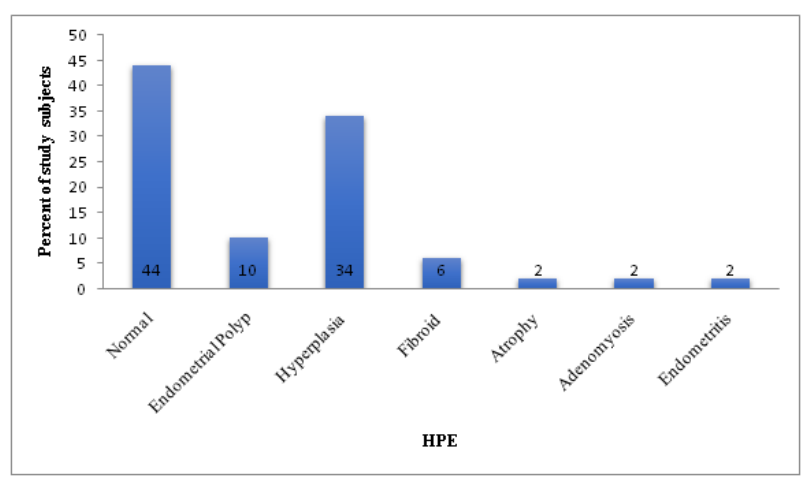

Figure 5: Distribution of study subjects according to HPE $(\mathrm{N}=50)$.

The present study was carried out amongst 50 patients in a tertiary care center with complaint of abnormal uterine bleeding with the objective to study the role of diagnostic hysteroscopy in evaluating abnormal uterine bleeding. The patients with abnormal uterine bleeding vary as per the age. In this study the most common age group was between 41 to 50 years contributing to $40 \%$. And the mean age was 38.78 years with a standard deviation of 8.2 (Figure 1). Thus, abnormal uterine bleeding was more commonly seen in reproductive age group and was slightly more common in perimenopausal age group.

\section{DISCUSSION}

Hysteroscopy is an important invention in the field of gynecology. Hysteroscopy helps to inspect the uterine cavity under direct vision as compared to blind curettage. As per the present study the most common age group to present with abnormal uterine bleeding was between 41 to 50 years. This was comparable to most of the studies conducted by Firdous et al, Naik et al and Valson et al. ${ }^{7-9}$ Menorrhagia was found to be the most common cause of abnormal uterine bleeding and was analogous to other studies lead by Firdous et al, Naik et al, Valson et al, Singh et al and Channareddy et al. ${ }^{7-11}$ Most common duration of symptoms as per our study was 6-12 months with a mean of 8.07 months with SD of 4.32. These results could be correlated to a study conducted by Singh et al in March 2017 on 150 patients presenting with AUB, $42.7 \%$ of patients presented within a duration of 6 months to 1 years. ${ }^{10}$ On ultrasonographic findings, the most common finding was polyp diagnosed in 9 patients $(18 \%)$, this was followed by fibroid in 4 patients $(8 \%)$.As per a study conducted by Naik et al in 2017 on 350 patient USG detected abnormality in $65.6 \%$ of cases and $34.4 \%$ were normal on USG but majority of these were fibroids and ovarian cysts. ${ }^{8}$ However, diagnosis of specific intrauterine pathology was made in only 45 cases $(12.8 \%)$. According to the present study, the most common finding on hysteroscopy was endometrial hyperplasia which was seen in 16 patients contributing to $32 \%$, followed by endometrial polyp and uterine fibroids being $12 \%$ and $8 \%$ of the patients respectively. These results were comparable to other studies with endometrial hyperplasia being most common finding ranging from $14.6 \%$ to $27 \%$ of patients Firdous et al , Naik et al, Valson et al, Singh et al. ${ }^{7-10}$

The most common finding of histopathology as per the present study was endometrial hyperplasia seen in 17 patients $(34 \%)$, followed by endometrial polyp seen in 5 patients (10\%). These results were comparable to various studies performed by Firdous et al, Valson et al, Channareddy et al where endometrial hyperplasia was the most common pathology seen on histopathology which was followed by endometrial polyp. ${ }^{7,9,13}$ The approach used in this study helps us to correlate ultrasonographic and hysteroscopic findings and histopathological results easily. $^{12}$

\section{Comparison of ultrasonographic findings with histopathological examination}

There were thirty-three patients who showed normal ultrasonographic findings of which 20 were found to be normal on histopathological examinations while 12 $(24 \%)$ patients were suggestive of hyperplasia. One patient with normal findings on USG showed endometritis on histopathological examination. Of the nine patients with evidence polyp on ultrasonography, 4 showed polyps on histopathological examination, other four showed features suggestive of hyperplasia. While one patient showed normal studies on histopathological examination. Of the 4 fibroids detected on ultrasonography, three patients showed fibroid on histopathological examination, one was found to be polyp on histopathology. Two patients were suggestive of adenomyosis on ultrasonography of which one co-related on histopathological examination, while other showed endometrial hyperplasia on histopathology. One patient with features suggestive of atrophy on ultrasonography showed atrophy on histopathological examination. While the one with evidence of IUCD in situ on ultrasonography showed normal studies histopathology (Table 2). 
Table 2: Comparison of USG Findings with HPE (N=50).

\begin{tabular}{|c|c|c|c|c|c|c|c|c|}
\hline \multirow{2}{*}{ USG Findings } & \multicolumn{8}{|l|}{ HPE } \\
\hline & Normal & Polyp & Hyperplasia & Fibroid & Atrophy & Adeno-myosis & Endometritis & Total \\
\hline $\begin{array}{l}\text { Endometrial } \\
\text { Polyp }\end{array}$ & 1 & 4 & 4 & & & & & 9 \\
\hline Fibroid & & 1 & & 3 & & & & 4 \\
\hline Adenomyosis & & & 1 & & & 1 & & 2 \\
\hline IUCD & 1 & & & & & & & 1 \\
\hline Atrophy & & & & & 1 & & & 1 \\
\hline Normal & 20 & & 12 & & & & 1 & 33 \\
\hline Total & 22 & 5 & 17 & 3 & 1 & 1 & 1 & 50 \\
\hline
\end{tabular}

Table 3: Comparison of validities of USG and HPE $(\mathbf{N}=\mathbf{5 0})$.

\begin{tabular}{|c|c|c|}
\hline \multirow[t]{2}{*}{ USG } & \multicolumn{2}{|l|}{ HPE } \\
\hline & Abnormal & Normal \\
\hline Abnormal & $15(\mathrm{TP})$ & $2(\mathrm{FP})$ \\
\hline Normal & $13(\mathrm{FN})$ & $20(\mathrm{TN})$ \\
\hline
\end{tabular}

Comparison between hysteroscopy and histopathological examination: Of the 22 patients with normal hysteroscopic examination, 20 patients showed normal histopathological findings on histopathological report. One patient with normal hysteroscopic findings showed adenomyosis on histopathological examination. One patient with normal findings on hysteroscopy showed atrophic changes on histopathology. Of the 16 patients with endometrial hyperplasia on hysteroscopy, 15 showed endometrial hyperplasia on hysteroscopic examinations which were consistent with histopathological findings. And 1 patient with evidence of endometrial hyperplasia on hysteroscopy showed normal findings on histopathology.

Table 4: Comparison of hysteroscopy with HPE (N=50).

\begin{tabular}{|c|c|c|c|c|c|c|c|c|}
\hline \multirow{2}{*}{ Hysteroscopy } & \multicolumn{8}{|l|}{ HPE } \\
\hline & Normal & Polyp & Hyperplasia & Fibroid & Atrophy & Adeno-myosis & Endometritis & Total \\
\hline Normal & 20 & & & & 1 & 1 & & 22 \\
\hline $\begin{array}{l}\text { Endometrial } \\
\text { Polyp }\end{array}$ & & 5 & 1 & & & & & 6 \\
\hline Fibroids & & & 1 & 3 & & & & 4 \\
\hline IUCD & 1 & & & & & & & 1 \\
\hline Hyperplastic & 1 & & 15 & & & & & 16 \\
\hline Adhesions & & & & & & & 1 & 1 \\
\hline Total & 22 & 5 & 17 & 3 & 1 & 1 & 1 & 50 \\
\hline
\end{tabular}

Table 5: Comparison of validities of hysteroscopy \& histopathology $(\mathrm{N}=\mathbf{5 0})$.

\begin{tabular}{|lll|}
\hline Hysteroscopy & $\begin{array}{l}\text { HPE } \\
\text { Abnormal }\end{array}$ & Normal \\
\hline Abnormal & $26(\mathrm{TP})$ & $2(\mathrm{FP})$ \\
\hline Normal & $2(\mathrm{FN})$ & $20(\mathrm{TN})$ \\
\hline
\end{tabular}

Four patients were diagnosed with submucosal fibroid on hysteroscopy of which one was diagnosed with hyperplasia on histopathology. Rest 3 patients showed same findings on histopathological examination. 6 patients showed submucosal polyp on hysteroscopic findings of which 5 patients with endometrial polyp on hysteroscopy showed consistent findings on histopathology while one showed endometrial hyperplasia. One patient showed adhesion on hysteroscopy, showed endometritis on HPE examination. One patient showed IUCD on hysteroscopy with normal findings on hysteroscopic examination (Table 3). Thus, the sensitivity and specificity of hysteroscopy are $92.9 \%$ and $90.9 \%$ respectively whereas the PPV and NPV are 92.9 and 90.9 respectively.

\section{Comparison of validities of hysteroscopy \& histopathology $(N=50)$.}

These results are comparable with studies conducted by Firdous et al in 2017 with sensitivity and specificity of $93.2 \%$ and $83.9 \%$ respectively. Also, the positive and negative predictive values were comparable with this study (Table 4). 
Table 6: Comparing the validities of hysteroscopy with other studies.

\begin{tabular}{|lllll|}
\hline Study & $\begin{array}{l}\text { Sensitivity } \\
(\%)\end{array}$ & $\begin{array}{l}\text { Specificity } \\
(\%)\end{array}$ & PPV & $\begin{array}{l}\text { NP } \\
\text { V }\end{array}$ \\
\hline $\begin{array}{l}\text { Present } \\
\text { Study }\end{array}$ & 92.9 & 90.9 & 92.9 & $\begin{array}{l}90 . \\
9\end{array}$ \\
\hline $\begin{array}{l}\text { Firdous } \\
\text { et al }\end{array}$ & 93.2 & 83.9 & 82 & 94 \\
\hline $\begin{array}{l}\text { Singh et } \\
\text { al }\end{array}$ & 79 & 93 & & \\
\hline $\begin{array}{l}\text { Valson } \\
\text { et al }\end{array}$ & 90.9 & 96.4 & 95.2 & \\
\hline
\end{tabular}

\section{Correlation between hysteroscopy and USG}

As per this study there were 22 and 33 patients with normal findings on hysteroscopy and USG respectively. Of these 19 patients with normal findings on hysteroscopy had normal findings on USG as well. Remaining 15 patients with normal ultrasonographic findings, 11 had features suggestive hyperplasia, 1 patient showed evidence of polyp on hysteroscopy while, one patient with multiple adhesions on hysteroscopy while three were suggestive of submucosal myoma.

Table 7: Comparison of hysteroscopy with USG ( $N=50)$.

\begin{tabular}{|c|c|c|c|c|c|c|c|}
\hline \multirow{2}{*}{ USG } & \multicolumn{6}{|c|}{ Hysteroscopy } & \multirow{2}{*}{ Total } \\
\hline & Normal & Polyp & Hyperplasia & Fibroid & IUCD & Adhesion & \\
\hline Endometrial Polyp & 1 & 4 & 4 & & & & 9 \\
\hline Fibroid & & 1 & & 3 & & & 4 \\
\hline Adenomyosis & 1 & & 1 & & & & 2 \\
\hline IUCD & & & & & 1 & & 1 \\
\hline Atrophy & 1 & & & & & & 1 \\
\hline Normal & 19 & 1 & 11 & 1 & & 1 & 33 \\
\hline Total & 22 & 6 & 16 & 4 & 1 & 1 & 50 \\
\hline
\end{tabular}

Table 8: Comparison of validities of USG \& hysteroscopy $(\mathbf{N}=\mathbf{5 0})$.

\begin{tabular}{|lll|}
\hline Validities & USG & Hysteroscopy \\
\hline Sensitivity & 53.6 & 92.9 \\
\hline Specificity & 90.9 & 90.9 \\
\hline PPV & 88.2 & 92.9 \\
\hline NPV & 60.6 & 90.9 \\
\hline
\end{tabular}

Of the 9 patients diagnosed with polyp on ultrasonography, 4 patients had consistent findings on hysteroscopy, 4 showed features suggestive of hyperplasia while 1 showed normal findings. 4 patients were diagnosed with submucosal fibroid on USG, of these 3 were diagnosed as fibroid on hysteroscopy and one was diagnosed as endometrial polyp. One of normal findings on hysteroscopy was found to have atrophic changes on USG. One patient with IUCD in situ on USG showed IUCD with normal endometrium on hysteroscopy. Two patients diagnosed with adenomyosis on USG, showed one normal finding while showed hyperplastic changes on hysteroscopy (Table 5). Therefore, from the above table it is observed that hysteroscopy has more sensitivity and PPV as compared to USG for diagnosing patients with abnormal uterine bleeding.

\section{CONCLUSION}

This study concludes that hysteroscopy has a definitive role in evaluation of patients presenting with abnormal uterine bleeding as hysteroscopy is a reliable and a safe procedure with high sensitivity, specificity, PPV and NPV in the diagnosis of abnormal uterine bleeding with immediate results. Hysteroscopy and histopathology complement each other in the evaluation of patient with abnormal uterine bleeding thus helping in further treatment of patients presenting with abnormal uterine bleeding as the accuracy of diagnosis in finding the cause of abnormal uterine bleeding is more.

Funding: No funding sources

Conflict of interest: None declared

Ethical approval: The study was approved by the Institutional Ethics Committee

\section{REFERENCES}

1. Bhatta S, Sinha AK. Histopathological study of endometrium in abnormal uterine bleeding. J Pathol Nepal. 2012;2(4):297-300.

2. Munro MG. Abnormal uterine bleeding in the reproductive years. Part I-Pathogenesis and clinical investigation. J Am Assoc Gynecol Laparoscop. 1999;6(4):391-419

3. Mishra D, Sultan S. FIGO'S PALM-COEIN Classification of abnormal uterine bleeding: A Clinico-Histopathological correlation in Indian setting. J Obstet Gynecol India. 2017;67(2):119-25.

4. Gimpelson RJ, Rappold HO. A comparative study between panoramic hysteroscopy with directed 
biopsies and dilatation and curettage: a review of 276 cases. Am J Obstet Gynecol. 1988;158(3):489-92.

5. Nezhat C, Nezhat F, Nezhat C. Nezhat's operative gynecologic laparoscopy and hysteroscopy. London: Cambridge University Press; 2008.

6. Tarneja P, Duggal BS. Hysteroscopy: Past, present and future. Med J Armed Forces India. 2002;58(4): 293.

7. Firdous N, Mukhtar S, Bilal S, Beigh SK. Role of hysteroscopy and histopathology in evaluating patients with abnormal uterine bleeding. Int J Reprod Contracept Obstet Gynecol. 2018;6(2):615-9.

8. Naik M. Hysteroscopy in evaluation of intrauterine causes of AUB. Int J Reprod Contracept Obstet Gynecol. 2017;6(11):4835-9.

9. Valson H, Kulkarni C, Mukerjee S, Gowda SN. The role of diagnostic hysteroscopy in abnormal uterine bleeding and its histopathological correlation following blind dilatation and curettage. Int J Reprod Contracept Obstet Gynecol. 2016;5(3):609-14.
10. Amrita S, Monika A. The evaluative role of diagnostic hysteroscopy and ultrasonography in abnormal uterine bleeding. Int J Res Med Sci. 2017; 5:45-9.

11. Channareddy S, Somalatha R. Clinical study of diagnostic hysteroscopy in abnormal uterine bleeding and its histopathological correlation. IOSR J Dent Med Sci. 2013;5(13):45-9.

12. Elbareg AM, Elmahashi MO, Essadi FM. Evaluation of intrauterine pathology: efficacy of diagnostic hysteroscopy in comparison to histopathological examination. Reprod Syst Sex Disord. 2015;4(149):2.

Cite this article as: Mohite AM, Kapote DS, Fonseca M. Role of diagnostic hysteroscopy in evaluating patients with abnormal uterine bleeding in a tertiary care centre. Int J Reprod Contracept Obstet Gynecol 2021:10:4464-70. 